\title{
Neutralizing monoclonal antibodies define two different functional sites in human interleukin-4
}

\author{
Petra REUSCH', Stefan ARNOLD', Christoph HEUSSER ${ }^{2}$, Kathrin WAGNER ${ }^{2}$, Beverly WESTON ${ }^{3}$ and Walter SEBALD ${ }^{1}$ \\ 1 Theodor-Boveri-Institut für Biowissenschaften (Biozentrum) der Universität, Würzburg, Germany \\ 2 Ciba-Geigy Ltd, Pharmaceutical Research Department, Basel, Switzerland \\ ${ }^{3}$ SmithKline Beecham Pharmaceuticals, Biosciences Research Centre, Epsom, England
}

(Received December 29, 1993) - EJB 93 1932/1

\begin{abstract}
Human interleukin-4 (IL-4) is a small four-helix-bundle protein which is essential for organizing defense reactions against macroparasites, in particular helminths. Human IL-4 also appears to exert a pathophysiological role during various IgE-mediated allergic diseases. Seven different monoclonal antibodies neutralizing the activity of human IL-4 were studied in order to identify functionally important epitopes. A collection of 41 purified IL- 4 variants was used to analyse how defined amino acid replacements affect binding affinity for each individual $\mathrm{mAb}$. Specific amino acid positions could be assigned to four different epitopes. mAbs recognizing epitopes on helix $\mathrm{A}$ and/or $\mathrm{C}$ interfered with IL-4 receptor binding and thus inhibited IL-4 function. However, other mAbs also inhibiting IL-4 function recognized an epitope on helix D of $\mathrm{IL}-4$ and did not inhibit IL-4 binding to the receptor protein. One mAb, recognizing $\mathrm{N}$-terminal and $\mathrm{C}$-terminal residues, partially competed for binding to the receptor. The results of these $\mathrm{mAb}$ epitope analyses confirm and extend previous data on the functional consequences of the amino acid replacements which showed that amino acid residues in helices $\mathrm{A}$ and $\mathrm{C}$ of IL- 4 provide a binding site for the cloned IL- 4 receptor and that a signalling site in helix D interacts with a further receptor protein.
\end{abstract}

The formation of homo-oligomers or hetero-oligomers appears to be the crucial event during activation and transmembrane signalling of cytokine receptors (Taga et al., 1989; Miyajima et al., 1992a, 1992b; Murakami et al., 1993). For certain receptor systems oligomerisation has been shown to be mediated by different receptor-binding sites exposed on the surface of the cytokine ligand. For example, human growth hormone has two binding sites promoting the formation of a homodimeric growth-hormone-receptor complex by the sequential binding of two identical receptor subunits (Cunningham et al., 1991; Ultsch et al., 1991; De Vos et al., 1992). Mouse interleukin-2 has three binding sites allowing the formation of a heterotrimeric receptor complex consisting of an $\alpha, \beta$ and $\gamma$-subunit (Waldmann, 1991; Taniguchi and Minami, 1993; Voss et al., 1993). Experiments in this study using neutralizing monoclonal antibodies (mAbs) support the notion of the existence of two distinct functional sites in human interleukin-4 (IL-4).

Human IL-4 is a small four-helix-bundle protein of 129 amino acid residues that is essential for initiating defense reactions against parasites, in particular helminths (Paul, 1991 ; Sher and Coffman, 1992). Human IL-4 also appears to

Correspondence to W. Sebald, Theodor-Boveri-Institut für Biowissenschaften (Biozentrum) der Universität, Physiologische Chemie II, Am Hubland, D-97074 Würzburg, Germany

Fax: +499318884113.

Abbreviations. IL-4, interleukin-4; $\mathrm{EC}_{50}$, effector concentration resulting in half-maximal response; $R_{\text {inax }}$, maximal response obtained at saturation levels; $\mathrm{IC}_{50}$, concentration resulting in half-maximal inhibition; IL-4R, soluble IL-4 receptor; [K61Q]IL-4, interleukin-4 in which lysine at position 61 has been replaced by glutamine. exert a pathophysiological role during IgE-mediated allergic diseases (Finkelman et al., 1990; Romagnani, 1990). Recently, a series of human IL-4 variants has been generated by in vitro mutagenesis (Kruse et al., 1991, 1992, 1993). Analysis of bioactivity and receptor binding revealed the occurrence of variants affected in IL-4 receptor binding (characterized by an increased concentration affecting the halfmaximal response, $\mathrm{EC}_{50}$ ) and variants affected in receptor activation (characterized by a reduced maximal response obtained at saturation levels, $R_{\max }$ ). The $\mathrm{EC}_{50}$ variants had been modified at amino acid positions in helices $\mathrm{A}$ and $\mathrm{C}$, whereas the $R_{\max }$ variants originated from amino acid substitutions in helix $\mathrm{D}$. Thus, two functionally distinct sites appear to be present in human IL-4 which might promote the formation of the activated receptor oligomer.

The binding site and the activation site in human IL-4 should also be detected and defined by analysing the epitopes recognized by monoclonal antibodies (mAbs) neutralizing the bioactivity. Such $\mathrm{mAbs}$ have been generated by several groups, since they represent important analytical tools for dissecting the function and biosynthesis of IL-4 (Ohara and Paul, 1985; Chrètien et al., 1989; Solari et al., 1989). Furthermore, they are of potential therapeutic use as $\mathrm{IL}-4$ antagonists in vivo (Tepper et al., 1989, 1990; Urban et al., 1991).

The seven IL- 4 neutralizing mAbs used in the present study were analysed by means of 41 purified IL- 4 variants modified at defined single amino acid positions. Altered binding affinities between certain combinations of $\mathrm{mAbs}$ and IL-4 variants allowed the localization of at least four different binding regions. Epitopes on helices $\mathrm{C}$ and $\mathrm{D}$ of hu- 
man IL-4 have been identified recently by competition experiments employing peptides representing particular segments (Ramanathan et al., 1993). Whereas these results provide preliminary evidence for a homodimeric IL-4 receptor, the present data strongly suggest a heterodimeric $I L-4$ receptor system.

\section{MATERIALS AND METHODS}

\section{Materials}

Recombinant human $\mathrm{IL}-4$ and mutant proteins were produced in Escherichia coli and purified as described previously (Weigel et al., 1989; Kruse et al., 1991, 1992, 1993). The IL-4 variants used in the present study have been designated as follows: H1Q; C3T; D4N; E9Q; E9K; C24T; E26Q; K37Q; E41Q; E43Q; C46T; R47Q; R53Q; Y56D; H59Q; K61Q; C65T; R81E; R85Q; R88Q; R88D; W91R; C99T; E103Q; E103K; E114Q; K117Q; M120D; R121D; K123D; K123E; Y124D; Y124G; Y124F; Y124H; Y124K; Y124N; S125D; C127T; C127D; S128D. The number in the designation of the variants indicates the position altered by in vitro mutagenesis. The amino acid originally present in IL-4 is indicated by the first letter and the substituted amino acid by the second letter, both using the one-letter code. $\mathrm{Mu}$ tant proteins binding to the mAbs with affinities comparable to that of IL-4 are underlined (Tables 2 and 3).

The soluble IL-4 receptor (IL-4R $R_{e x}$ ) was expressed in CHO cells and purified by affinity chromatography with IL-4 coupled to CNBr-activated Sepharose 4B (Pharmacia; Kruse et al., 1993). $\left[{ }^{3} \mathrm{H}\right]$ thymidine and $\mathrm{Na}^{125} \mathrm{I}$ were obtained from Amersham; $N$-hydroxysuccinimido long-chain biotin and secondary antibody (goat anti-mouse IgG/alkaline phosphatase conjugate) were from Pierce. RPMI 1640, fetal calf serum and other cell culture reagents were supplied by Biochrom.

\section{Monoclonal antibodies}

mAbs to human IL-4 were generated according to Galfrè and Milstein (1981) and Peters and Baumgarten (1990). The mAbs 1G1, 4D9, 7D7, and 8F12 were generated in the laboratory of Dr C. Heusser (Andersson et al., 1990), mAbs 3IIID6 and 3VD4 were established in the laboratories of Prof. W. Sebald and mAb 3B9 was selected by Dr B. Weston and coworkers. The immunization of $\mathrm{Balb} / \mathrm{c}$ mice was performed using recombinant human IL-4 and Freund's adjuvant. Mouse spleen cells were fused with either NS/O or PAI myeloma cells. After two weeks, the culture supernatants of fusion products were screened by ELISA using antigencoated microtiter plates or by RIA using sheep anti-mouse Ig coated plates and ${ }^{125} \mathrm{I}$-labeled IL-4. The concentration of mAbs purified by established procedures (Harlow and Lane, 1988) was determined spectrophotometrically with an antibody concentration of $1 \mathrm{mg} / \mathrm{ml}$ yielding an absorbance of 1.35 at $280 \mathrm{~nm}$.

\section{T-cell proliferation assay}

Inhibition of T-cell proliferation (measured as detailed in Solari et al., 1989) was expressed as the molar concentration $\left(\mathrm{IC}_{50}\right)$ of antibody that decreases by $50 \%$ the T-cell proliferation activity of recombinant human IL-4. The inhibitory constant $K_{\mathrm{i}}$ was determined using the equation $K_{\mathrm{i}}=\mathrm{IC}_{50} /$ $\left(1+[\mathrm{L}] / \mathrm{EC}_{\mathrm{so}}\right)$ with [L] representing the concentration of recombinant human $\mathrm{IL}-4$ and $\mathrm{EC}_{50}$ the IL-4 concentration lead- ing to half-maximal proliferation of the T-cells in this system $(0.2 \mathrm{nM})$.

\section{Protein modifications}

Biotinylation of recombinant human $\mathrm{IL}-4$ or $\mathrm{IL}-4 \mathrm{R}_{\mathrm{ex}}$ was performed according to the manufacturers instructions at a fivefold molar excess of $N$-hydroxysuccinimido long-chain biotin over IL-4 or $\Pi$ L- $4 R_{\text {ex }}$. Recombinant human IL-4 was radioactively labeled with ${ }^{125} I$ using the IODO-GEN $(1,3,4,6-$ tetrachloro-3 $\alpha, 6 \alpha$-diphenyl glycouril) method (Pierce) as described previously (Cabrillat et al., 1987). The specific radioactivity was determined in a solid phase competition assay as described (Kruse et al., 1993). The specific radioactivity of ${ }^{125}$ I-labeled IL-4 was $0.5-0.8 \mu \mathrm{Ci} / \mathrm{pmol} \mathrm{IL}-4$.

\section{ELISA techniques}

Binding of mAbs to recombinant human IL-4 and mutant proteins was measured in a competitive ELISA (Harlow and Lane, 1988; Hornbeck et al., 1991). Flexible assay plates (Falcon MicroTest III) were coated with streptavidin and blocked. Biotinylated $\Pi-4(90 \mathrm{pg} / \mathrm{ml})$ was bound to the streptavidin. After washing three times, mAbs at a constant concentration $(100-500 \mathrm{ng} / \mathrm{ml})$ were incubated with $\log 2 \mathrm{di}$ lutions of competitor (wild type IL-4 or mutant protein). After three washes, a secondary antibody (anti-mouse IgG/alkaline phosphatase conjugate) diluted 1:2000 was added. The plates were developed using $p$-nitrophenyl phosphate as substrate and the absorbance at $405 \mathrm{~nm}$ was measured using a microplate reader (Dynatech). From the inhibition curves, the $\mathrm{IC}_{50}$ value describing the competitor concentration allowing half-maximal binding of mAb to IL-4 on the solid phase was determined. The relative binding of mutant protein was described as $\mathrm{IC}_{50}$ (variant)/ $/ \mathrm{C}_{50}$ (wild-type $\mathrm{IL}-4$ ).

$\mathrm{mAb}$ competition groups were established by measuring the competition between two mAbs (one immobilised on a microtiter plate, one in solution) for binding of biotinylated IL-4.

Binding of mAbs to recombinant human IL-4 fixed to IL-4R $R_{\text {ex }}$ was analysed by sandwich ELISA. The microtiter plates were coated with streptavidin and blocked as described for competitive ELISA. Biotinylated $I L-4 R_{e x}$ was added $(100 \mathrm{pg} / \mathrm{ml})$ for $1 \mathrm{~h}$ followed by incubation with recombinant human IL-4 $(2 \mu \mathrm{g} / \mathrm{ml})$ for $2 \mathrm{~h}$. After three washes, $\log 2$ dilutions of mAbs starting with $10 \mu \mathrm{g} / \mathrm{ml}$ were added. The following steps were performed as for competitive ELISA.

\section{Spot peptide synthesis and $\mathbf{m A b}$ binding assay}

Epitope mapping experiments by means of spot peptide synthesis were performed according to the manufacturer's instructions (Cambridge Research Biochemicals; Frank and Döring, 1988; Blankemeyer-Menge et al., 1990). Overlapping decapeptides covering the whole amino acid sequence of human IL-4 were synthesized on cellulose paper. The binding of mAb $3 \mathrm{~B} 9$ to the peptides was analysed using a peroxidase-conjugated anti-mouse IgG (Dianova). The luminescence (Thorpe and Kricka, 1986) of the substrate (luminole) was detected by a Kodak X-OMAT film.

\section{RIA techniques}

To test the reactivity of mAbs $1 \mathrm{G1}, 4 \mathrm{D} 9,7 \mathrm{D} 7$ and $8 \mathrm{~F} 12$ with wild type $\Pi L-4$ and mutant proteins, microtiter plates 


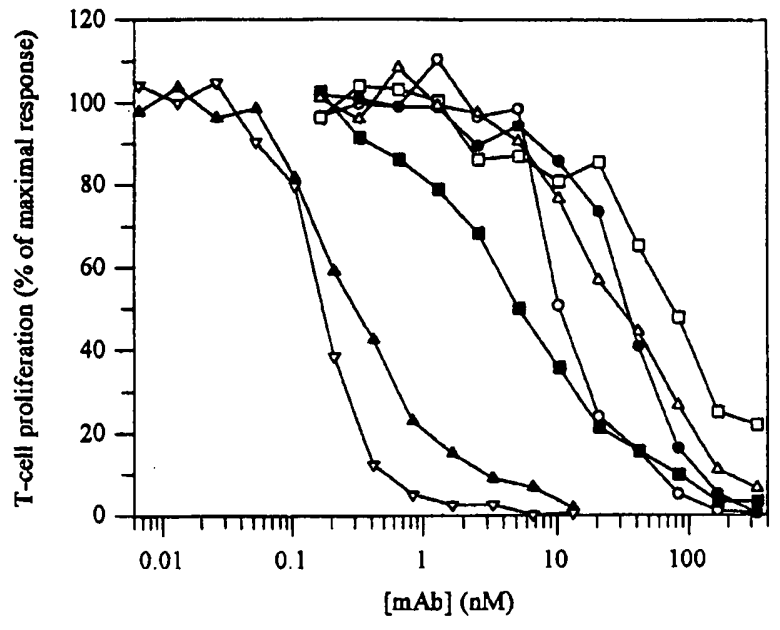

Fig. 1. Inhibition of IL-4 dependent T-cell proliferation by mAbs. Phytohemagglutinin-stimulated human T-cells were incubated with $0.34 \mathrm{nM} \mathrm{IL}-4$ plus the indicated concentration of mAbs 3IIID6 $(O)$,

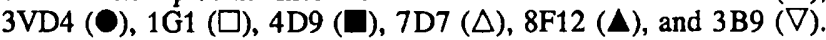
T-cell proliferation was determined by $\left[{ }^{3} \mathrm{H}\right]$ thymidine incorporation.

were coated with mAbs $(20 \mu \mathrm{g} / \mathrm{ml}) .{ }^{125} \mathrm{I}$-labeled IL-4 (1 nM) and competitor (wild-type IL-4 or mutant protein, $27 \mathrm{nM}$ ) were incubated on the plates for $1 \mathrm{~h}$. The plates were washed three times and bound radioactivity was measured in a gamma counter (Packard Cobra 5005). The values given in Table 3 represent the inhibition of IL -4 binding by competitor, expressed by the following equation:

$$
I=100\left(\mathrm{cpm}_{\max }-\mathrm{cpm}_{\mathrm{x}}\right) / \mathrm{cpm}_{\max },
$$

with $I$ defining the inhibition (\%), $\mathrm{cpm}_{\max }$ the maximal bound radioactivity in absence of competitor and $\mathrm{cpm}_{\mathrm{x}}$ the bound radioactivity in the presence of competitor.

\section{Receptor-binding assay on T-cells}

Binding of ${ }^{125} \mathrm{I}$-labeled IL-4 to T-cells was performed as described previously (Kruse et al., 1992). Briefly, human Tcells prestimulated with phytohemagglutinin were incubated with $0.8 \mathrm{nM}^{125} \mathrm{I}$-labeled IL-4 in the presence of various concentrations of mAb (300 nM-1 pM). Separation of the cells from free IL-4 was achieved by centrifugation through silicon oil. The bound radioactivity was determined in a gamma counter (Beckmann). $K_{\mathrm{i}}$ values were calculated using the equation $K_{\mathrm{i}}=\mathrm{IC}_{50} /\left(1+[\mathrm{L}] / K_{\mathrm{d}}\right)$ with $\mathrm{IC}_{50}$ describing the $\mathrm{mAb}$ concentration reducing the IL-4 binding to $50 \%$ of the maximal value, [L] the concentration of ${ }^{125}$ I-labeled IL- 4 and $K_{d}$ the dissociation constant of IL-4 for the IL-4 receptor $(100 \mathrm{pM})$.

\section{RESULTS}

\section{Properties of monoclonal antibodies}

All mAbs used in the present study were raised against recombinant human $\mathrm{IL}-4$ produced in $E$. coli and belong to the subclass IgG1. These mAbs inhibited IL-4-dependent T-cell proliferation (Fig. 1), with mAb 3B9 and 8F12 being effective at doses stoichiometric to the applied IL-4 $\left(K_{\mathrm{i}} 60-\right.$
Table 1. Properties of monoclonal antibodies. In Western blots, the signal strength was scored strong $(+++)$, fair $(+)$, or no reaction (-) for binding of $\mathrm{mAb}$ to recombinant human IL-4 blotted onto nitrocellulose membrane. The inhibitory constants $K_{1}$ of the $\mathrm{mAbs}$ during a T-cell proliferation assay were determined from the $\mathrm{IC}_{50}$ values (Fig. 1) as detailed in the Materials and Methods section.

\begin{tabular}{llllc}
\hline mAb & Subtype & $\begin{array}{l}\text { Binding } \\
\text { to IL-4 in } \\
\text { Western blots }\end{array}$ & $\begin{array}{l}\text { Competition } \\
\text { group }\end{array}$ & $K_{\mathbf{i}}$ \\
\hline & & & & $\mathrm{nM}$ \\
3IIID6 & IgG1 & +++ & III & 3.9 \\
3VD4 & IgG1 & - & I & 13 \\
3B9 & IgG1 & +++ & IV & 0.06 \\
1G1 & IgG1 & - & II & 29 \\
4D9 & IgG1 & + & I & 1.7 \\
7D7 & IgG1 & - & II & 11 \\
8F12 & IgG1 & +++ & I & 0.1 \\
\hline
\end{tabular}

$100 \mathrm{pM}$ ) whereas the other mAbs showed lower inhibitory activities with $K_{\mathrm{i}}$ values of $2-30 \mathrm{nM}$ (see Table 1 ).

During spot-blot and Western-blot analysis, mAbs 3IIID6, 3B9 and 8F12 reacted equally with native and denatured IL-4 at amounts smaller than $10 \mathrm{ng}$. mAb 4D9 bound with lower affinity to the denatured IL-4 and the binding of mAbs 3VD4,1G1 and 7D7 could not be measured even with large amounts of the denatured protein.

The mAbs could be divided into four groups with overlapping binding regions as determined by competition of two mAbs for IL-4 binding (data not shown), with group I comprising mAbs 3VD4, 4D9 and 8F12, group II comprising mAbs $1 \mathrm{G} 1$ and 7D7. mAb 3IIID6 represents group III and 3B9 represents group IV.

\section{Altered binding of certain IL-4 variants to specific mAbs as measured by competitive ELISA}

Biotinylated IL-4 immobilized on streptavidin-coated wells of a microtiter plate was specifically recognized by the seven mAbs shown in Table 2 . All mAbs, with the exception of $1 \mathrm{G} 1$ and $7 \mathrm{D} 7$, also bound to $\mathrm{IL}-4$ directly coated onto the plates. The competition between immobilized IL- 4 and soluble IL-4 or IL-4 variants for binding to the mAbs could be quantitatively determined by means of an alkaline-phosphatase-linked secondary antibody. Serial dilutions of the soluble proteins yielded dose/inhibition curves as shown in Fig. 2, from which the concentration effecting $50 \%$ inhibition $\left(\mathrm{IC}_{\mathrm{s0}}\right)$ could be derived. The examples employing $\mathrm{mAb} 7 \mathrm{D} 7$ shown in Fig. 2 represent (a) variant [K61Q]IL-4 binding with an $\mathrm{IC}_{50}$ similar to IL-4 (relative $\mathrm{IC}_{50}$ approximately 1), (b) a variant [R88Q]IL-4 with very low affinity (relative $\mathrm{IC}_{50}>30$ ), (c) a variant [R53Q]IL-4 with low affinity (relative $\mathrm{IC}_{50}$ approximately 10 ) and (d) a variant [Y56D] L-4 with slightly reduced affinity (relative $\mathrm{IC}_{50}$ approximately 3 ).

The relative $\mathrm{IC}_{50}$ values indicating a loss of binding affinity could thus be classified into four categories as compiled in Table 2 showing one of two independent measurements performed with the indicated $\mathrm{mAbs}$ and $\mathrm{IL}-4$ variants. A subset of 12 of the $\Pi L-4$ variants (see Materials and Methods section; underlined variants) bound during the competitive ELISA to all $\mathrm{mAbs}$ with affinities which differed not measurably from those of $\mathrm{L}-4$, and these variants are therefore not included in the table. A few variants, i.e. [H59Q], [C3T], $[\mathrm{C} 24 \mathrm{~T}],[\mathrm{C} 65 \mathrm{~T}]$ and $[\mathrm{C} 127 \mathrm{~T}] \mathrm{L}-4$, generally showed a 


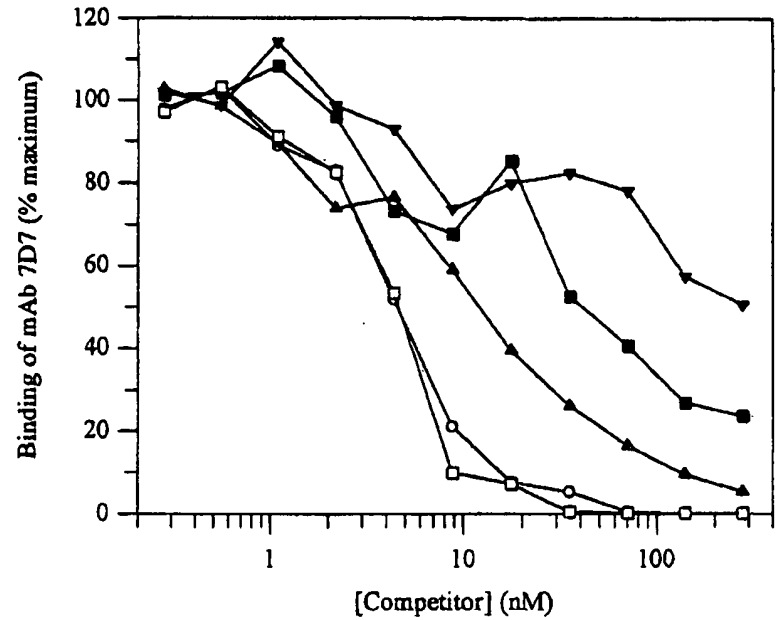

Fig. 2. Competition of $\mathrm{IL}-4$ variants for binding of $\mathrm{mAb} 7 \mathrm{D7}$ to immobilized $I-4$ as measured during ELISA. The variants chosen as typical examples demonstrate the competition at the indicated concentrations of IL-4 (O) and of variants K61Q ( $\square)$, Y56D (A), R53Q ( $\mathbf{\square})$, and R88Q ( $\mathbf{\nabla}$.

slightly reduced reactivity to all mAbs $\left(\mathrm{IC}_{50}\right.$ of $\left.2-4\right)$. These variants most likely are structurally disturbed and therefore react to a lower extent (data not shown). Three variants, i.e. [C46T], [C99T], [M120D]IL-4, showed a strongly reduced reactivity to all mAbs. The conformation of these variants appears to be highly impaired (Kruse et al., 1991).
The other IL-4 variants exhibit very specific and pronounced binding deficiencies with certain mAbs only, as indicated in Table 2 . mAb 3IIID6 did not measurably react with variant [S128D]IL-4. Binding was reduced strongly with variants [D4N], [Y124D/G] and [C127D]IL-4, and to a minor extent with variants [H1Q]IL-4 and [K123D]IL-4. The three-dimensional structure of IL-4 (Fig. 4) demonstrates that the side chains affected in these variants are located at the $\mathrm{C}$-terminus and N-terminus near to each other as expected if they were to form part of a common epitope interacting with mAb 3IIID6.

A second pattern emerged with mAbs 3VD4, 4D9 and 8 F12, which all react very poorly with variant [E114Q]IL-4 modified in helix D. mAbs 3VD4 and 4D9 were in addition very sensitive to the amino acid replacement in variant [R121D]IL-4. The epitopes recognized by this group of mAbs comprise residues on helix D.

A third group of mAbs, i.e. 1G1 and 7D7, showed low reactivity with variants [R88D]IL-4 and [W91R]IL-4. In addition, mAb 7D7 did not bind to variant [E9K] reactivity with variants $[R 47 \mathrm{Q}],[\mathrm{R} 53 \mathrm{Q}]$ and $[\mathrm{R} 81 \mathrm{E}] \mathrm{IL}-4$ was reduced. These patterns probably indicate epitopes overlapping at the lower end of helix $\mathrm{C}$ and extending with $\mathrm{mAb}$ $7 D 7$ to the upper $\mathrm{N}$-terminal region of helix $\mathrm{B}$ and helix $\mathrm{A}$.

mAb 3B9, which in this study has the highest potency in inhibiting IL-4 bioactivity, revealed a loss of reactivity with only one of the available variants, i.e. [R81 E]IL-4 (with the exception of the extensively denatured variants). Apparently, the epitope of mAb $3 \mathrm{~B} 9$ extends over the $\mathrm{N}$-terminal region of helix C. Binding analysis by means of spot peptides synthesized on paper sheets (Frank and Döring, 1988; Blanken-

Table 2. Loss of binding affinity of $\mathbf{I L}-4$ variants to mAbs measured by means of competitive ELISA. The IL-4 variants with binding affinities similar to Il- 4 were omitted from the table (see Materials and Methods section). The relative $\mathrm{IC}_{50}$ values of these variants were used to calculate the cut-off value (mean $\pm S D$ ). No entries in the table signify that the measured value was below the cut-off value. XXX, $\mathrm{IC}_{50}$ values more than 30 -fold higher than the $\mathrm{IC}_{50}$ of $\mathrm{IL}-4 ; \mathrm{XX}$, a 10-29-fold increased $\mathrm{IC}_{50}$ value; X, a 5-9.9-fold increase in IC 50 ; $(\mathrm{X})$, $\mathrm{IC}_{50}$ values increased less than 4.9 -fold.

\begin{tabular}{|c|c|c|c|c|c|c|c|}
\hline \multirow[t]{2}{*}{ IL-4 variant } & \multicolumn{7}{|c|}{ Monoclonal antibody } \\
\hline & 3IIID6 & 3VD4 & 4D9 & $8 \mathrm{~F} 12$ & $1 \mathrm{G1}$ & $7 \mathrm{D} 7$ & $3 \mathrm{~B} 9$ \\
\hline $\begin{array}{l}\text { H1Q } \\
\text { D4N } \\
\text { E9Q } \\
\text { E9K } \\
\text { R47Q } \\
\text { R53Q } \\
\text { Y56D } \\
\text { R81E } \\
\text { R85Q } \\
\text { R88Q } \\
\text { R88D } \\
\text { W91R } \\
\text { E114Q } \\
\text { K117Q } \\
\text { R121D } \\
\text { K123D } \\
\text { K123E } \\
\text { Y124D } \\
\text { Y124G } \\
\text { C127D } \\
\text { S128D }\end{array}$ & $\begin{array}{l}(\mathrm{X}) \\
\mathbf{X X} \\
\mathbf{X X} \\
\mathbf{X X} \\
\mathbf{X X X}\end{array}$ & $\begin{array}{l}\mathrm{XXX} \\
\mathrm{X} \\
\mathrm{XXX} \\
\mathrm{X}\end{array}$ & $\begin{array}{l}\mathrm{XXX} \\
(\mathrm{X}) \\
\mathrm{XXX}\end{array}$ & $\begin{array}{l}X X X \\
(X)\end{array}$ & $\begin{array}{l}\text { XXX } \\
\text { XXX }\end{array}$ & $\begin{array}{l}\mathrm{XXX} \\
\mathrm{X} \\
\mathrm{X} \\
\mathrm{XX} \\
\\
\mathrm{XXX} \\
\mathrm{XXX} \\
\mathrm{XXX}\end{array}$ & $\mathrm{XXX}$ \\
\hline $\begin{array}{l}\text { Mean } \\
\text { SD } \\
\text { Cut-off value }\end{array}$ & $\begin{array}{l}1.50 \\
1.00 \\
2.5\end{array}$ & $\begin{array}{l}2.00 \\
2.00 \\
4\end{array}$ & $\begin{array}{l}1.50 \\
0.50 \\
2\end{array}$ & $\begin{array}{l}1.50 \\
1.00 \\
2.5\end{array}$ & $\begin{array}{l}2.00 \\
1.50 \\
3.5\end{array}$ & $\begin{array}{l}2.00 \\
1.50 \\
3.5\end{array}$ & $\begin{array}{l}1.00 \\
0.50 \\
1.5\end{array}$ \\
\hline
\end{tabular}


68

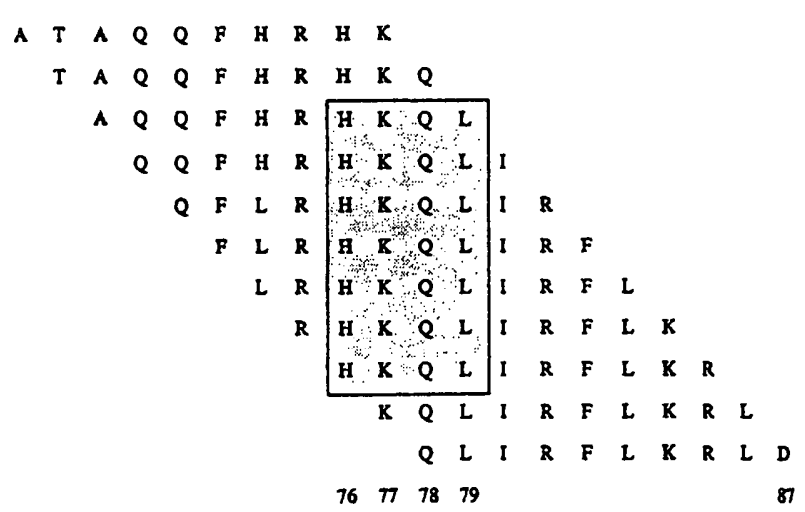

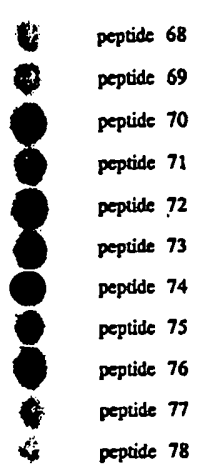

Fig. 3. A synthetic nested set of IL-4 decapeptides binds specifically to mAb 3B9. The spot-peptide-synthesis method (BlankemeyerMenge and Frank, 1990) was used to synthesize 120 nested decapeptides fixed in spots on a paper. The consecutive peptides, each shifted by one amino acid position, represent the whole IL-4 protein sequence. The paper was incubated with mAb 3B9, and bound 3B9 was detected by a secondary antibody conjugate as shown at the right side of the figure.

Table 3. Inhibition of $\mathrm{IL}-4$ binding to mAbs by $\mathrm{IL}-4$ variants. The symbols indicate the inhibition of binding of ${ }^{125}$ I-labeled $\mathrm{IL}-4$ to indicated mAbs as induced by various IL-4 variants. The cut-off value was set arbitrarily at the mean value minus three times the standard deviation measured for the binding of the other unconspicuous variants (see Materials and Methods section) to each $\mathrm{mAb}$. No entries in the table indicate no change in inhibition of the variant compared to wild-type IL-4; XXX, XX and X indicate an inhibition lower than the mean value minus five, four or three times, respectively, the standard deviation.

\begin{tabular}{lllll}
\hline IL-4 variant & \multicolumn{3}{l}{ Monoclonal antibody } & \\
\cline { 2 - 5 } & $4 \mathrm{D9}$ & $8 \mathrm{~F} 12$ & $1 \mathrm{G} 1$ & $7 \mathrm{D} 7$ \\
\hline E9K & & & & $\mathrm{X}$ \\
R53Q & & & & $\mathrm{X}$ \\
Y56D & & & & \\
H59Q & & & & $\mathrm{X}$ \\
R88Q & & & $\mathrm{XX}$ & $\mathrm{X}$ \\
R88D & $\mathrm{XXX}$ & $\mathrm{XX}$ & $\mathrm{XX}$ & $\mathrm{X}$ \\
W91R & $\mathrm{X}$ & & & \\
E114Q & $\mathrm{XXX}$ & $\mathrm{XX}$ & & \\
K117Q & 66 & 66 & 69 & 66 \\
R121D & 13 & 13 & 11 & 16 \\
Mean & 27 & 27 & 36 & 18 \\
SD & & & & \\
Cut-off value &
\end{tabular}

meyer-Menge et al., 1990) revealed that partial sequences comprising residues His76, Lys77, Gln78 and Leu79 react specifically with mAb 3B9 (Fig. 3). These residues are also located on the N-terminal region of $\mathrm{IL}-4$ helix $\mathrm{C}$.

\section{Reactivity of $\mathbf{I L}-4$ variants}

with $\mathrm{mAb}$ during radioligand binding

The reactivity of the $\Pi \mathrm{L}-4$ variants with mAbs $1 \mathrm{G} 1,4 \mathrm{D}$, 7D7 and 8F12 was analysed independently by means of a radioimmunoassay. This experimental setup should be less prone to possible artefacts originating from immobilizing IL-4 to the plastic surface. The results compiled in Table 3 show that the binding of ${ }^{125} \mathrm{I}-$ labeled $\mathrm{IL}-4$ to for example mAb $1 \mathrm{G} 1$ is inhibited by $69 \pm 11 \%$ (mean $\pm \mathrm{SD}$ ) in the pres- ence of $26.7 \mathrm{nM} \mathrm{IL-4}$ or most of the variants. Competition is significantly less, however, with variants [W91R]IL-4 or [R88D]IL-4. In the case of mAb 7D7, loss of binding occurred in variants [E9K], [R53Q], [R88Q/D] and [W91R]IL4. The competition with mAb 4D9 revealed reduced affinities to variants [E114Q], [K117Q] and [R121D]L-4. Pronounced binding deficiencies were found for $\mathrm{mAb} 8 \mathrm{~F} 12$ in the case of variants [E114Q]IL-4 and [R121D]IL-4. These results largely confirm the data obtained by means of ELISA but some differences are evident. For example, [R121 D]IL4 was a poor ligand for mAb 8F12 during RIA but not during ELISA. Defects in recognition of variant [R47Q]IL-4 by mAb 7D7 could not be detected during the RIA experiments.

\section{Location of epitope residues on the three-dimensional structure of $\mathrm{IL}-4$}

The epitope residues identified during ELISA and RIA form patches on the surface of the IL-4 protein as depicted in Fig. 4. The largest clusters were identified with mAbs 7D7 and 3IIID6. The surface areas on IL-4 postulated to form an epitope have dimensions of approximately $2 \mathrm{~nm} \times 2 \mathrm{~nm}$ for $7 \mathrm{D} 7$ and $1.5 \times 1.5 \mathrm{~nm}$ for 3IIID6 (Müller, T., unpublished results). It is interesting to note that the competition groups of the analysed $\mathrm{mAb}$, as shown in Table 1 , are compatible with the localization of the epitopes. Some overlap appears to exist in the case of Arg81 which might interact with mAbs from different groups (3B9 and 7D7).

\section{Competition between mAbs and soluble $I L-4$ receptor ( $\left(L-4 R_{e x}\right.$ ) for $I L-4$ binding}

The central issue of this study concerns the alignment of $\mathrm{mAb}$ epitopes and IL-4-receptor-binding sites. This problem could be addressed employing the extracellular binding domain of the known $I L-4$ receptor (IL- $4 R_{\text {ex }}$ ) isolated from the culture medium of transfected $\mathrm{CHO}$ cells.

The recombinant extracellular domain of $I L-4 R_{e x}$ immobilized in the wells of microtiter plates binds IL-4 with $K_{\mathrm{d}}$ approximately $100 \mathrm{pM}$ (Kruse et al., 1993), similar to the receptor on $\mathrm{T}$ cells or $\mathrm{B}$ cells. The recognition of receptorbound IL- 4 by the various mAbs is demonstrated by the results of saturation binding experiments as shown in Fig. 5 . mAbs 3B9, 1G1 and 7D7 do not bind up to concentrations 

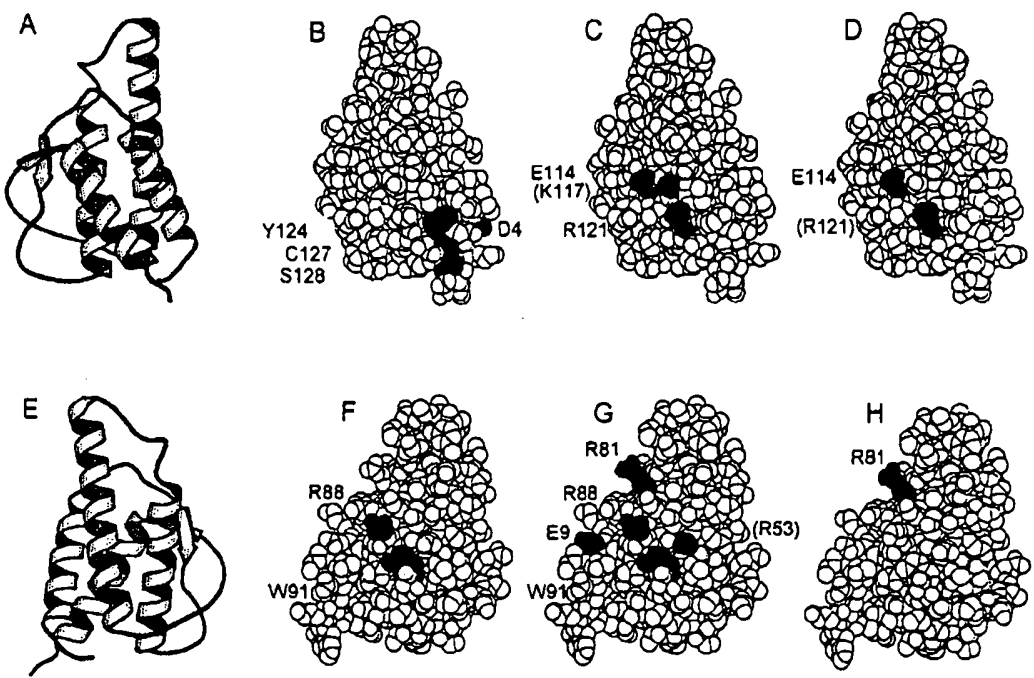

Fig. 4. Location on a space-filling human IL-4 model of epitope residues for neutralizing mAbs as identified by the experiments described in Tables 2 and 3. A and E represent a model of the overall structure of IL-4 indicating the positions of the helices. The space filling models indicate the positions of epitope side chains for mAb 3IIID6 (B), 3VD4 and 4D9 (C), 8F12 (D), 1G1 (F), 7D7 (G) and 3B9 $(\mathrm{H})$. The upper row shows a view for helices D and A; elsewhere, a view of IL-4 helices C and B is depicted. The amino acid side chains which upon modification specifically weaken the binding of one mAb are shaded and designated by the one letter code. From Table 2 , only amino acid positions yielding a relative $\mathrm{IC}_{50}>10$ were considered. Amino acid positions drawn in brackets indicate that a change in binding could be detected only in one of the two assays, i.e. either ELISA or RIA.

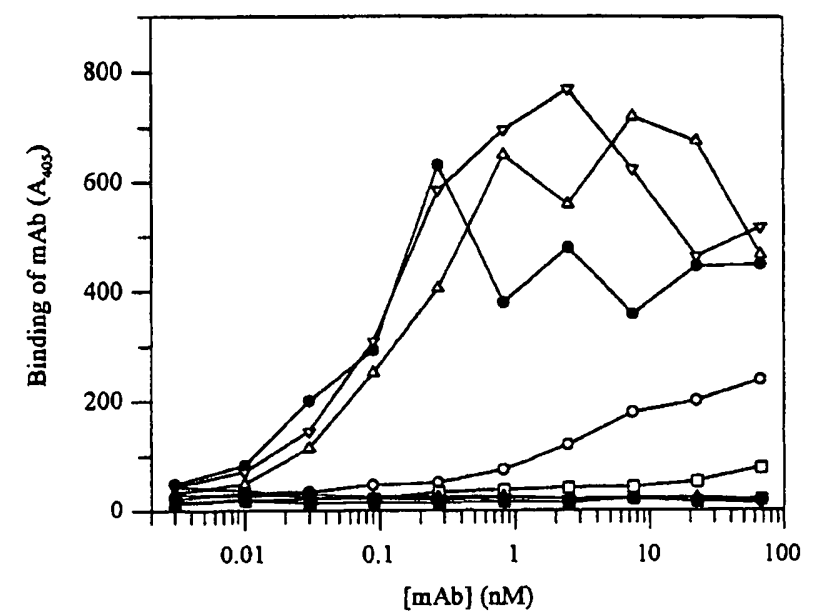

Fig. 5. Binding of $\mathrm{mAbs}$ to the $\mathrm{IL}-4 / \mathrm{IL}-4$ receptor complex. IL-4 was attached to biotinylated IL-4R $\mathrm{R}_{\mathrm{ex}}$ immobilized in the wells of a microtiter plate. The individual wells were incubated with the indicated concentrations of mAb 3IIID6 (O), 3VD4 (0), 3B9 (D), 1G1 $(\mathbb{C}), 4 \mathrm{D} 9(\Delta), 7 \mathrm{D} 7(\Delta), 8 \mathrm{~F} 12(\nabla)$, and a control IgG1 $(\nabla)$. Bound $\mathrm{mAb}$ was measured by a second alkaline-phosphatase-conjugated antibody.

of $67 \mathrm{nM}$. The same background levels are observed with an isotype matched control mAb. This indicates that the bound receptor blocks the epitopes for these groups of antibodies. In contrast, saturation binding to a high level is found with mAbs 3VD4, 4D9 and 8F12. mAb 3IIID6 also binds, albeit only at higher concentrations, so that saturation probably has not been achieved under the experimental conditions. The binding was specific, since it depended completely on bound IL-4 during the assay (data not shown). This indicates that the epitopes of these groups of mAbs are spatially separated from the receptor-binding sites on IL-4, so that a simul- taneous binding to IL-4 of both $\mathrm{IL}-4 \mathrm{R}_{\mathrm{ex}}$ and $\mathrm{mAb}$ is sterically possible.

In a second set of experiments it could be demonstrated that mAbs 3B9, 1G1 and 7D7 inhibited binding of ${ }^{125} \mathrm{I}$-labeled IL-4 to the immobilized IL-4R $\mathrm{R}_{\text {ex }}$ whereas the presence even of a large molar excess of mAbs 3IIID6, 3VD4, 4D9 and 8F12 showed only minor effects (data not shown), thus confirming the results obtained in the sandwich ELISA.

\section{Influence of mAbs $3 B 9$ and $8 F 12$ on the binding of IL- 4 to T-cells}

During the present study, it has been shown that mAbs $3 \mathrm{~B} 9$ and 8F12 inhibit the IL-4-induced T-cell proliferation at doses nearly stoichiometric to the applied IL-4 concentration $\left(K_{\mathrm{j}} 60 \mathrm{pM}\right.$ and $\left.100 \mathrm{pM}\right)$. The two mAbs exhibited a different effect, however, on binding of IL-4 to the isolated soluble $\mathrm{IL}-4$ receptor. mAb $3 \mathrm{~B} 9$ blocked binding of $\mathrm{IL}-4$ to $\mathrm{IL}-4 \mathrm{R}_{\mathrm{ex}}$ completely, whereas mAb 8F12 could bind IL-4 simultaneously with IL-4R $\mathrm{R}_{\mathrm{ex}}$ (Fig. 5). Thus, it was interesting to analyse how these mAbs influence IL-4 binding to the functional receptor present on T-cells. As shown in Fig. 6, mAb 3B9 blocked binding of ${ }^{125} \mathrm{I}$-labeled $\Pi \mathrm{L}-4$ to the cellular receptor with an $\mathrm{IC}_{50}$ of $300 \mathrm{pM}$, corresponding to a $K_{\mathrm{i}}$ of $40 \mathrm{pM}$, whereas for $8 \mathrm{~F} 12$ a more than 100 -fold larger $\mathrm{IC}_{50}$ of $65 \mathrm{nM}$ was determined $\left(K_{\mathrm{i}} \approx 10 \mathrm{nM}\right)$. Since T-cell proliferation is inhibited at a much lower concentration, it is reasonable to conclude that mAb $8 \mathrm{~F} 12$ is able to interact with $\mathrm{IL}-4$ bound to the functional receptor on T-cells.

\section{DISCUSSION}

The neutralizing monoclonal antibodies studied during the present experiments discriminate two functionally important sites in human IL-4. One site is recognized by a group of $\mathrm{mAbs}$ which compete with the known receptor protein for 


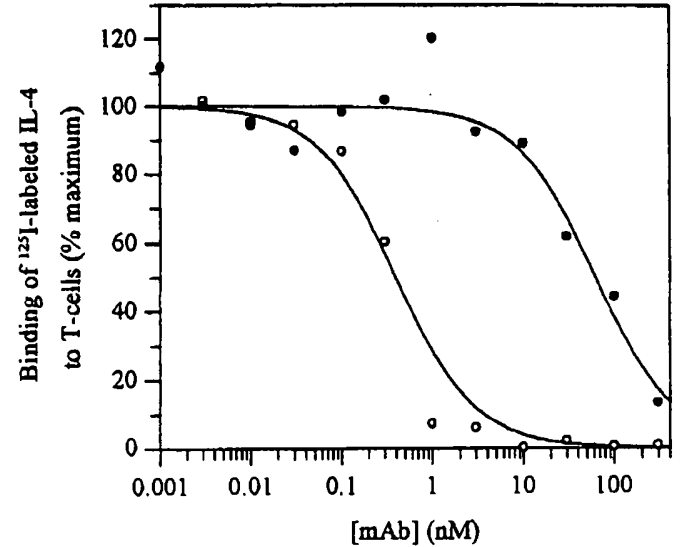

Fig. 6. Inhibition of $\mathrm{IL}-4$ binding to T-cells by mAbs $3 \mathrm{B9}$ and 8F12. T-cells were incubated with ${ }^{125} \mathrm{I}$-labeled IL-4 plus the indicated concentrations of mAbs 3B9 (O) or 8F12 (O). Bound ${ }^{125} \mathrm{I}$ labeled IL-4 was determined and calculated relative to maximal binding (in the absence of $\mathrm{mAb}$ ).

IL- 4 binding. The second site is detected by those mAbs which are able to bind to IL-4 simultaneously with the receptor protein. The IL-4 variants used in this study have been analysed before with respect to biological activity, physical receptor binding and structural integrity (Kruse et al., 1991, 1992,1993 ) and turned out to be valuable tools in marking the epitopes of all seven mAbs employed in this study. Our mutational epitope scanning approach allowed the mapping of discontinuous or conformational epitopes which are difficult to analyse by other techniques. Moreover, low-affinity mAbs can be analysed. The epitope of one mAb (3B9) could be demarcated also by the spot-peptide-synthesis method.

The epitope residues identified during the presented experiments cover major parts of the accessible surfaces of helices $\mathrm{A}-\mathrm{D}$. In the $\mathrm{N}$-terminus and in helix $\mathrm{A}$, informative amino acid exchanges occurred at the positions of His1, Asp4 and Glu9. No data could be obtained for the distal part of helix A. The major part of helix $\mathrm{C}$ was tagged by diagnostic variants [R81E], [R85Q], [R88Q/D] and [W91R]IL-4. Nearly along the whole surface of helix $D$, residues were found that contributed to different epitopes, i.e. Glu114, Lys117, Arg121, Tyr124 and Ser128. Finally, one residue on helix B (Arg53) is involved in binding to mAb 7D7. X-ray analyses of antibody/antigen complexes have shown that in the case of lysozyme (Amit et al., 1986; Sheriff et al., 1987) and influenza virus neuraminidase (Colman et al., 1987) contact areas are approximately $2.5 \mathrm{~nm} \times 2 \mathrm{~nm}$ and comprise 15-17 amino acid residues. Accordingly, even the $\mathrm{IL}-4$ contact residues identified for mAbs 7D7 and 3IIID6 most likely represent only part of the complete epitopes. The present results do not exactly define the borders between the individual epitopes. Competition experiments employing pairs of mAbs in all possible combinations revealed the existence of four groups: two mAbs each from a different group can bind simultaneously to $\mathbb{L}-4$. Since the competition binding was not analysed quantitatively, it might be possible that the epitopes of mAbs from different groups overlap partially, and that the first $\mathrm{mAb}$ attached to IL-4 lowers the binding affinity for the second $\mathrm{mAb}$. The amino acid side chain of Arg81 belonging to both the 3B9 and the 7D7 epitope might represent such an overlap.

mAbs 3B9 (group IV) and 7D7/1G1 (group II) competed efficiently with $\mathrm{IL}-4 \mathrm{R}_{\mathrm{ex}}$ for IL-4 binding. The identified IL-4 epitope residues for the group II and group IV mAbs therefore provide new informations on the binding site of IL-4 for the known receptor protein. The epitope of $\mathrm{mAb} 7 \mathrm{D} 7$ comprises side chains of Glu9 and Arg88. Arg88 also resides in the epitope of $\mathrm{mAb} 1 \mathrm{G} 1$. Both side chains have been previously identified to interact with IL-4R 1993), because variants $[E 9 Q / K] \Pi L-4$ and $[R 88 Q / D] I L-4$ bind with reduced affinities to the receptor ( $\mathrm{EC}_{50}$ variants). The finding that epitope residues of $\mathrm{mAb} 3 \mathrm{~B} 9$ are localized at the proximal N-terminal region of helix $\mathrm{C}$, strongly suggests that the IL- 4 binding site for IL- $4 \mathrm{R}_{\text {ex }}$ extends to this part of the protein. This conclusion is also in accordance with a recent study (Ramanathan et al., 1993) that human IL-4 variants [K84I], [R88Q/T] and [N89D]IL-4 are deficient in bioactivity and receptor binding.

The most important conclusion drawn from the present results is that the IL-4 binding site for $\Pi L-4 R_{\text {ex }}$ does not extend to helix D and probably does not extend to the N-terminal residues up to Asp4. This conclusion rests on the observation that the group I and III mAbs, whose epitopes are located in these areas, interfere only weakly (3IIID6) or marginally (3VD4, 4D9, 8F12) with IL-4R ex binding. mAb 8F12 inhibits receptor binding of IL- 4 only at more than 100 -fold higher concentrations than that necessary to inhibit IL-4-dependent T-cell proliferation. This small residual inhibitory activity for $\mathrm{IL}-4 \mathrm{R}_{\mathrm{ex}}$ binding may be due to a small overlap between the $8 \mathrm{~F} 12$ epitope and the receptor-binding site, as the epitope borders are not defined clearly and the binding site for mAb 8F12 may extend onto helix $A$ at undefined positions. The present findings contrast with a recent study on a rat mAb $25 \mathrm{D} 2$ neutralizing human $\mathrm{IL}-4$ bioactivity and receptor binding at an equally low concentration $(0.33 \mathrm{nM})$ and interacting with an IL-4 peptide comprising C-terminal residues 104-129 (Ramanathan et al., 1993). These results are not necessarily at variance with the present results, since the epitope of rat mAb 25D2 could extend substantially into the binding site of $\mathrm{IL}-4 \mathrm{R}_{\mathrm{ex}}$, most likely onto IL-4 helix A. It is interesting to note that in the human IL-6 system, a group of $\mathrm{mAbs}$ was found which neutralized IL- 6 bioactivity without inhibiting IL-6 binding to U266 cells (Brakenhoff et al., 1990, 1992). Possibly, these mAbs block the binding site on human IL-6 for gp130, but do not interfere with IL-6 binding to the low affinity receptor (IL-6R $\alpha$ ).

What might be the explanation for the IL-4 neutralizing activity of group II and group III mAbs (3VD4, 4D9, 8F12/ 3IIID6)? It is now generally agreed that the oligomerisation of receptor subunits represents the critical step leading to receptor activation. Applying an allosteric receptor-oligomerisation model (Schlessinger, 1988), these mAbs may block an allosteric signalling site on helix D of IL-4, thereby preventing a conformational change which would normally trigger receptor oligomerisation. Although such a mechanism cannot be formally excluded, several lines of recent evidence favour a sequential direct receptor oligomerisation via multiple binding sites on the IL-4 ligand. IL-4 is structurally related to growth hormone and the IL-4 receptor belongs to the same family of receptors as the growth-hormone-binding protein. Similar to the human growth hormone, IL-4 might first interact with $I L-4 R_{e x}$ via its binding site provided by residues on helices $A$ and $C$. This complex creates an interface including signalling residues on IL-4 helix D for the attachment of a second receptor subunit (Müller et al., 1994). An analysis of the charge distribution on human IL-4 and IL$4 \mathrm{R}_{\mathrm{ex}}$ (Demchuk, E., unpublished results) suggest the formation of a heterodimeric receptor, i.e. the second receptor sub- 
unit is not IL-4R $\mathrm{R}_{\mathrm{ex}}$. The recent finding of cross competition between human $\mathrm{IL}-4$ and human $\mathrm{IL}-13$ for binding to TF1 cells (Zurawski et al., 1993) would be consistent with a second receptor subunit common to the IL-4 and IL-13 systems. However, it could be also visualized that an IL-13binding protein interacts with a hetero-dimeric or homodimeric IL-4 receptor complex, similar to the complex of ciliary neurotrophic factor/ciliary neurotrophic-factor-binding protein interacting with a heterodimeric receptor complex (Davis et al., 1993).

Recent findings suggest that the $\gamma$-chain of the interleukin-2 receptor is a functional component of the IL-4 receptor (and also the interleukin-7 receptor) in murine as well as in human cells (Russell et al., 1993; Kondo et al., 1993; Noguchi et al., 1993). Thus, it is a reasonable assumption that the signalling site on helix D of human IL-4 interacts with this common $\gamma$-receptor subunit. It can be easily visualised that mAbs directed against the signalling site block binding of the common $\gamma$ chain and thereby inhibit the biological activity of IL-4 but not IL-4R $\mathrm{R}_{\mathrm{ex}}$ binding.

The present results stress the importance of C-terminal residues and the surface of helix $D$ for $I L-4$ bioactivity. The present study and a previous study reveal, however, that this region is not involved in binding to the known $\mathrm{IL}-4$ receptor as often discussed (Le et al., 1991; Morrison and Leder, 1992; Bamborough et al., 1993; Wlodawer et al., 1993; Ramanathan et al., 1993). It can be visualized that the two types of neutralizing anti-IL-4 mAbs (blocking or not blocking cell-surface receptor binding) behave differently in vivo. Possibly, organ distribution, clearance route and half life are different for a mAb binding to soluble IL-4 only and for a $\mathrm{mAb}$ also reacting with cell-bound IL-4.

We thank Dr J. Bews for the RIA measurements, Dr R. Frank for help and advice on the spot-peptide-synthesis method, Dr N. Kruse and Bo-Jiang Shen for preparation of the IL-4 variants, T. Müller for constructing the three-dimensional structures of IL-4 and $H$. Spengler for excellent technical assistance. This study was supported by Deutsche Forschungsgemeinschaft grant Se 435/2-2.

\section{REFERENCES}

Amit, A. G., Mariuzza, R. A., Phillips, S. E. V. \& Poljak, R. J. (1986) Three-dimensional structure of an antigen-antibody complex at $2.8 \AA$ resolution, Science $233,747-753$.

Andersson, U., Andersson, J., Lindfors, A., Wagner, K., Möller, G. \& Heusser, C. H. (1990) Simultaneous production of interleukin 2 , interleukin 4 and interferon- $\gamma$ by activated human blood lymphocytes, Eur. J. Immunol. 20, 1591-1596.

Bamborough, P., Grant, G. H., Hedgecock, C. J. R., West, S. P. \& Richards, W. G. (1993) A computer model of the interleukin-4/ receptor complex, Proteins Struct. Funct. Genet. 17, 11-19.

Blankemeyer-Menge, B. \& Frank, R. (1988) Simultaneous multiple synthesis of protected peptide fragments on Allyl-functionalized cellulose disc supports, Tetrahedron Lett. 29, 5871-5874.

Blankemeyer-Menge, B., Nimtz, M. \& Frank, R. (1990) An efficient method for anchoring FMOC-amino acids to hydroxyl-functionalised solid supports, Tetrahedron Lett. 31, 1701-1704.

Brakenhoff, J. P. J., Hart, M., De Groot, E. R., Di Padova, F. \& Aarden, L. A. .(1990) Structure-function analysis of human IL-6. Epitope mapping of neutralizing monoclonal antibodies with amino- and carboxyl-terminal deletion mutants, J. Immunol. $145,561-568$.

Brakenhoff, J. P. J., De Hon, F. D., Fontaine, V., Hart, M., De Groot, E. R., Content, J. \& Aarden, L. A. (1992) Two different sites on the IL-6 molecule are involved in biological activity, in $I L-6$ : physiopathology and clinical potentials. Serono symposia publications from Raven press (Revel, M., ed.) vol. 88, pp. 3341, Raven Press, New York.

Cabrillat, H., Galizzi, J.-P., Djossou, O., Arai, N., Yokota, T., Arai, K. \& Banchereau, J. (1987) High affinity binding of human interleukin 4 to cell lines, Biochem. Biophys. Res. Commun. 149, 995-1001.

Chrètien, I., Van Kimmenade, A., Pearce, M. K., Banchereau, J. \& Abrams, J. S. (1989) Development of polyclonal and monoclonal antibodies for immunoassay and neutralization of human interleukin-4, J. Immunol. Meth. 117, 67-81.

Colman, P. M., Laver, W. G., Varghese, J. N., Baker, A. T., Tulloch, P. A., Air, G. M. \& Webster, R. G. (1987) Three-dimensional structure of a complex of antibody with influenza virus neuraminidase, Nature 326, 358-363.

Cunningham, B. C., Ultsch, M., De Vos, A. M., Mulkerrin, M. G., Clauser, K. R \& Wells, J. A. (1991) Dimerization of the extracellular domain of the human growth-hormone-receptor by a single hormone molecule, Science 254, 821-825.

Davis, S., Aldrich, T. H., Stahl, N., Pan, L, Taga, T., Kishimoto, T., Ip, N. Y. \& Yancopoulos, G. D. (1993) LIFR $\beta$ and gp 130 as heterodimerizing signal transducers of the tripartite CNTF receptor, Science 260, 1805-1808.

De Vos, A. M., Ultsch, M. \& Kossiakoff, A. A. (1992) Human growth hormone and extracellular domain of its receptor: Crystal structure of the complex, Science 255, 306-312.

Finkelman, F. D., Holmes, J., Katona, I. M., Urban, J. F. Jr, Beckmann, M. P., Park, L. S., Schooley, K. A., Coffman, R. L., Mosmann, T. R. \& Paul, W. E. (1990) Lymphokine control of in vivo immunoglobulin isotype selection, Annu. Rev. Immunol. 8, 303333 .

Frank, R. \& Döring, R. (1988) Simultaneous multiple peptide synthesis under continuous flow conditions on cellulose paper discs as segmental solid supports, Tetrahedron 44, 6031-6040.

Galfrè, G. \& Milstein, C. (1981) Preparation of monoclonal antibodies: Strategies and procedures, Methods Enzymol. 73, 3-46.

Harlow, E. \& Lane, D. (1988) Antibodies: a laboratory manual, Cold Spring Harbor Laboratory, Cold Spring Harbor, New York.

Hornbeck, P., Winston, S. E. \& Iuller, S. A. (1991) Immunology in Current protocols in molecular biology (Ausubel, F. M, Brent, R., Kingston, R. E., Moore, D. D., Seidman, J. G., Smith, J. A. \& Struhl, K., eds) vol. 2, pp. 11.0.1-11.2.19, Green Publishing and Wiley \& Sons.

Kondo, M., Takeshita, T., Ishii, N., Nakamura, M., Watanabe, S., Arai, K.-I. \& Sugamura, K. (1993) Sharing of the interleukin-2 (IL-2) receptor $\gamma$ chain between receptors for IL-2 and IL-4, Science 262, 1874-1877.

Kruse, N., Lehmbecher, T. \& Sebald, W. (1991) Site-directed mutagenesis reveals the importance of disulfide bridges and aromatic residues for structure and proliferative activity of human interleukin-4, FEBS Lett. 286, 58-60.

Kruse, N., Tony, H.-P. \& Sebald, W. (1992) Conversion of human interleukin-4 into a high affinity antagonist by a single amino acid replacement, EMBO J. 11, 3237-3244.

Kruse, N., Shen, B.-J., Amold, S., Tony, H.-P., Müller, T. \& Sebald, W. (1993) Two distinct functional sites of human interleukin 4 are identified by variants impaired in either receptor binding or receptor activation, $E M B O \mathrm{~J} .12,5121-5129$.

Le, H. V., Seelig, G. F., Syto, R., Ramanathan, L., Windsor, W. T., Borkowski, D. \& Trotta, P. P. (1991) Selective proteolytic cleavage of recombinant human interleukin 4. Evidence for a critical role of the C-terminus, Biochemistry 30, 9576-9582.

Miyajima, A., Hara, T. \& Kitamura, T. (1992a) Common subunits of cytokine receptors and the functional redundancy of cytokines, Trends Biochem. Sci. 17, 378-382.

Miyajima, A., Kitamura, T., Harada, N., Yokota, T. \& Arai, K.-I. (1992b) Cytokine receptors and signal transduction, Annu. Rev. Immunol. 10, 295-331.

Morrison, B. W. \& Leder, P. (1992) A receptor binding domain of mouse interleukin- 4 defined by a solid-phase binding assay and in vitro mutagenesis, J. Biol. Chem. 267, 11957-11963.

Müller, T., Sebald, W. \& Oschkinat, H. (1994) Aspects of receptor binding and signalling of interleukin- 4 investigated by site-di- 
rected mutagenesis and NMR spectroscopy, J. Mol. Biol. 237, 423.

Murakami, M., Hibi, M., Nakagawa, N., Nakagawa, T., Yasukawa, K., Yamanishi, K., Taga, T. \& Kishimoto, T. (1993) IL-6-induced homodimerization of gp 130 and associated activation of a tyrosine kinase, Science 260, 1808-1810.

Noguchi, M., Nakamura, Y., Russell, S. M., Ziegler, S. F., Tsang M., Cao, X. \& Leonard, W. J. (1993) Interleukin-2 receptor $\gamma$ chain: A functional component of the Interleukin-7 receptor, Science 262, 1877-1880.

Ohara, J. \& Paul, W. E. (1985) Production of a monoclonal antibody to and molecular characterization of B-cell stimulatory factor-1, Nature 315, 333-336.

Paul, W. E. (1991) Interleukin-4: A prototypic immunoregulatory lymphokine, Blood 77, 1859-1870.

Peters, G. H. \& Baumgarten, H. (1990) Monoklonale Antikörper. 2., Springer, Berlin, Heidelberg, New York.

Ramanathan, L., Ingram, R., Sullivan, L., Greenberg, R., Reim, R., Trotta, P. P. \& Le H. V. (1993) Immunochemical mapping of domains in human interleukin 4 recognized by neutralizing monoclonal antibodies, Biochemistry 32, 3549-3556.

Romagnani, S. (1990) Regulation and deregulation of human $\operatorname{IgE}$ synthesis, Immunol. Today 11, 316-321.

Russell, S. M., Keegan, A. D., Harada, N., Nakamura, Y., Noguchi, M., Leland, P., Friedmann, M. C., Miyajima, A., Puri, R. K., Paul, W. E. \& Leonard, W. J. (1993) Interleukin-2 receptor $\gamma$ chain: A functional component of the interleukin-4 receptor, Science 262, 1880-1883.

Schlessinger, J. (1988) Signal transduction by allosteric receptor oligomerization, Trends Biochem. Sci. 13, 443-447.

Sher, A. \& Coffman, R. L. (1992) Regulation of immunity to parasites by $\mathrm{T}$ cells and $\mathrm{T}$ cell-derived cytokines, Annu. Rev. Immunol. 10, 385-409.

Sheriff, S., Silverton, E. W., Padlan, E. A., Cohen, G. H., SmithGill, S. J., Finzel, B. C. \& Davies, D. R. (1987) Three-dimensional structure of an antibody-antigen complex, Proc. Natl Acad. Sci. USA 84, 8075-8079.

Solari, R., Quint, D., Obray, H., McNamee, A., Bolton, E., Hissey, P., Champion, B., Zanders, E., Chaplin, A., Coomber, B., Watson, M., Roberts, B. \& Weir, M. (1989) Purification and charac- terization of recombinant human interleukin 4 , Biochem. J. 262 , 897-908.

Taga, T, Hibi, M., Hirata, Y, Yamasaki, K., Yasukawa, K., Matsuda, T., Hirano, T. \& Kishimoto, T. (1989) Interleukin-6 triggers the association of its receptor with a possible signal transducer, gp130, Cell 58, 573-581.

Taniguchi, T. \& Minami, Y. (1993) The IL-2/IL-2 receptor system: A current overview, Cell 73, 5-8.

Tepper, R. I., Pattengale, P. K. \& Leder, P. (1989) Murine interleukin-4 displays potent anti-tumor activity in vivo, Cell $57,503-$ 512.

Tepper, R. I., Levinson, D. A., Stanger, B. Z., Campos-Torres, J., Abbas, A. K. \& Leder, P. (1990) Il-4 induces allergic-like inflammatory disease and alters $\mathrm{T}$ cell development in transgenic mice, Cell 62, 457-467.

Thorpe, G. H. G. \& Kricka, L. J. (1986) Enhanced chemiluminescent reactions catalyzed by horseradish peroxidase, Methods Enzymol. 133, 331-353.

Ultsch, M., De Vos, A. M. \& Kossiakoff, A. A. (1991) Crystals of the complex between human growth hormone and the extracellular domain of its receptor, J. Mol. Biol. 222, 865-868.

Urban, J. F. Jr, Katona, I. M., Paul, W. E. \& Finkelman, F. D. (1991) Interleukin 4 is important in protective immunity to a gastrointestinal nematode infection in mice, Proc. Natl Acad. Sci. USA $88,5513-5517$.

Voss, S. D., Leary, T. P., Sondel, P. M. \& Robb, R. J. (1993) Identification of a direct interaction between interleukin 2 and the p64 interleukin 2 receptor $\gamma$ chain, Proc. Natl Acad. Sci. USA $90,2428-2432$.

Waldmann, T. A. (1991) The interleukin-2 receptor, J. Biol. Chem. 266, 2681-2684

Weigel, U., Meyer, M. \& Sebald, W. (1989) Mutant proteins of human interleukin 2 . Renaturation yield, proliferative activity and receptor binding, Eur. J. Biochem. 180, 295-300.

Wlodawer, A., Pavlovski, A. \& Gustchina, A. (1993) Hematopoietic cytokines: Similarities and differences in the structures, with implications for receptor binding. Protein Sci. 2, 1373-1382.

Zurawski, S. M., Vega, F. Jr, Huyghe, B. \& Zurawski, G. (1993) Receptors for interleukin-13 and interleukin -4 are complex and share a novel component that functions in signal transduction, EMBO J. 12, 2663-2670. 